\title{
Estimating renal volume from CT: Is this is easiest way?
}

\author{
Hwang Gyun Jeon, MD \\ Department of Urology, Samsung Medical Center, Sungkyunkwan University School of Medicine, Seoul, Korea
}

See related article on page 189.

Cite as: Can Urol Assoc J 2013;7 (5-6): 193-4. http://dx.doi.org/10.5489/cuaj.1336

W e congratulate Breau and colleagues for demonstrating that there was good correlation between renal volume as measured by two techniques: the ellipsoid method and 3D volume measurement using specialized volumetric software with contrast-enhanced CT scans. ${ }^{1}$ The authors found that the ellipsoid method underestimated 3D volume $\left(170 \mathrm{~cm}^{3}\right.$ vs. $186 \mathrm{~cm}^{3}$, respectively), but that almost all were accurate $30 \%$; they also concluded that measuring renal volume is easy and reliable. They also suggested that $3 \mathrm{D}$ volume software is not needed for the estimation of differential renal function.

Other authors previously showed that the modified ellipsoid method can be performed quickly with high reproducibility and accuracy. ${ }^{2}$ They showed that the intraclass correlation coefficient (ICC) was higher $(r=0.95)$ in this study. However, we believe that the correlation between observers using the ellipsoid method is somewhat inferior to that of the method using 3D analysis software. Previously, we reported an ICC of 0.995 in donor patients, meaning that renal volume measurement by the $3 \mathrm{D}$ analysis software is highly reproducible and accurate. ${ }^{3}$ We believe that the ellipsoid method can only be used to measure split renal function in renal donors. In patients with renal masses or nonfunctional tissues, such as renal cysts, it is impossible to measure normally functioning renal parenchyma using the ellipsoid method. In addition, the correlation between two estimated renal volume and DTPA kidney scintigraphy was not shown in this study by Breau and colleagues. ${ }^{1}$ The question thus remains as to which result is more correlated with renal function.

With advancements and improvements in software and imaging modalities, renal volume can be easily measured by volumetric analysis using 3D analysis software for CT scans. To our knowledge, several researchers are interested in renal volume measurement, and there have been several reports that renal volume is correlated with glomerular filtration rate and split renal function in donor patients. We reported the usefulness of 3D analysis software for measuring renal volume. Renal volume as measured by the voxel count method was correlated with glomerular filtration rate, and preoperative kidney volume was a significant predictor of delayed renal function recovery in 222 donors after donor nephrectomy. ${ }^{3}$ We also reported, for the first time, the relationships among kidney volume, renal function and age in normal kidneys using a different program. ${ }^{4}$ Recently, researchers have focused on the importance of renal volume for predicting renal function after radical or partial nephrectomy in patients with renal cell carcinoma. We first reported the prognostic significance of preoperative renal volume for predicting renal function in patients with renal cell carcinoma who underwent radical or partial nephrectomy. ${ }^{5}$ To determine the relative impact of preservation of parenchymal volume on renal function after partial nephrectomy, a volumetric program could be used to measure the volume of functional parenchyma preoperatively and postoperatively after partial nephrectomy in the contralateral and operated kidneys. We believe that the ellipsoid method has limitations in these situations.

Even though renal volume can be measured using different methods, such as the ellipsoid formula, the automated segmentation algorithm, or manual tracing to exclude nonfunctional tissues, there is no established method or program that reflects renal function well in patients with renal cell carcinoma. Prospective study is needed to determine measurements that correlate well with renal function.

Competing interests: None declared. 


\section{References}

1. Breau RH, Clark E, Bruner B, et al. A simple method to estimate renal volume from computed tomography. Can Urol Assoc J 2013;7:189-92. http://dx.doi.org/10.5489/cuaj.1338

2. Soga S, Britz-Cunningham S, Kumamaru KK, et al. Comprehensive comparative study of computed tomography-based estimates of split renal function for potential renal donors: modified ellipsoid method and other CT-based methods. J Comput Assist Tomogr 2012;36:323-9. http://dx.doi.org/10.1097/RCT.0b013e318251db15

3. Jeon HG, Lee SR, Joo DJ, et al. Predictors of kidney volume change and delayed kidney function recovery after donor nephrectomy. J Urol 2010; 184:1057-63. http://dx.doi.org/10.1016/i.juro.2010.04.079
4. Gong IH, Hwang J, Choi DK, et al. Relationship among total kidney volume, renal function and age. J Urol 2012; 187:344-9. http://dx.doi.org/10.1016/i.juro.2011.09.005

5. Jeon HG, Gong IH, Hwang JH, et al. Prognostic significance of preoperative kidney volume for predicting renal function in renal cell carcinoma patients receiving a radical or partial nephrectomy. BJU Int 2012;109:1468-73. http://dx.doi.org/10.1111/i.1464-410X.2011.10531.x

Correspondence: Dr. Hwang Gyun Jeon Department of Urology, Samsung Medical Center, Sungkyunkwan University, School of Medicine, \#50, Irwon-Dong, Gangnam-Gu, Seoul, Korea 135710; yellowbac@daum.net

\section{CUAJ JAUC}

We are pleased to now offer online manuscript and review submission for CUAJ. As of January 1, 2013, $\mathrm{CUAJ}$ is only receiving papers through its online manuscript submission system.

Please take a moment to register. Registration is free and quick!

When you register, you will be able to:

- Register as an Author, Reader and Reviewer

- Check the status of your paper online 24 hours a day/7 days a week

- Submit papers anytime

- Easily access papers for review

- Get immediate access to any job opportunities and news

To register:

1. Go to http://journals.sfu.ca/cuaj/index.php/journal/user/register

2. Register yourself as an author (and reviewer if you want to review papers for CUAJ)

3. Once you are registered, you will receive an email with your username and password - these will give you access to the system and allow you access to the status of your article

To submit a paper:

1. Go to http://journals.sfu.ca/cuaj/index.php/journal/index

2. Using the LOGIN tab, enter your username and password (sent to you in an email)

3. Go to the Author tab and click on the "Start your submission" link

4. Follow the 5-step submission process

- $\quad$ Make sure you submit a blinded copy of the paper for review. A blinded paper means that any identifying information should be deleted from the paper (i.e., your name, institution, contact information).

- $\quad$ Your tables and figures should be submitted as supplementary files.

- Before you upload files to the system, be sure they are not open on your system (this may cause problems in uploading).

Once your paper is submitted, you can follow its track through our editorial process - please keep your username and password handy.

At the moment, you can still access older issues of CUAJ at www.cuaj.ca - however, within the next few months, we will be migrating all our past issues to this new site (while keeping the cuaj.ca domain name). If you have any questions, please email me. I would be happy to walk you through the process.

Josephine Sciortino, CUA Corporate Office

185 Dorval Avenue, Suite 401, Dorval, QC H9S 5J9

Tel: 514-395-0376, ext. 40; Fax: 514-395-1664

Email: josephine.sciortino@cua.org 